\title{
Magnolol protects against ischemic-reperfusion brain damage following oxygen-glucose deprivation and transient focal cerebral ischemia
}

\author{
SHENG-YANG HUANG ${ }^{1,2 *}$, SHIH-HUANG TAI ${ }^{2 *}$, CHE-CHAO CHANG $^{2}$, \\ YI-FANG TU ${ }^{2,3}$, CHIH-HAN CHANG ${ }^{1}$ and E-JIAN LEE ${ }^{2}$ \\ ${ }^{1}$ Institute of Biomedical Engineering, National Cheng Kung University; ${ }^{2}$ Neurophysiology Laboratory, \\ Department of Surgery, National Cheng Kung University Medical Center and Medical School; \\ ${ }^{3}$ Department of Paediatrics, National Cheng Kung University Hospital, Tainan 70428, Taiwan, R.O.C.
}

Received March 19, 2017; Accepted December 21, 2017

DOI: $10.3892 / \mathrm{ijmm} .2018 .3387$

\begin{abstract}
In the present study, the neuroprotective potential of magnolol against ischemia-reperfusion brain injury was examined via in vivo and in vitro experiments. Magnolol exhibited strong radical scavenging and antioxidant activity, and significantly inhibited the production of interleukin-6, tumor necrosis factor-a and nitrite/nitrate $\left(\mathrm{NO}_{\mathrm{X}}\right)$ in lipopolysaccharide-stimulated BV2 and RAW 264.7 cells when applied at concentrations of 10 and $50 \mu \mathrm{M}$, respectively. Magnolol $(100 \mu \mathrm{M})$ also significantly attenuated oxygen-glucose deprivation-induced damage in neonatal rat hippocampal slice cultures, when administered up to $4 \mathrm{~h}$ following the insult. In a rat model of stable ischemia, compared with a vehicle-treated ischemic control, pretreatment with magnolol $(0.01-1 \mathrm{mg} / \mathrm{kg}$, intravenously) significantly reduced brain infarction following ischemic stroke, and post-treatment with magnolol $(1 \mathrm{mg} / \mathrm{kg})$ remained effective and significantly reduced infarction when administered $2 \mathrm{~h}$ following the onset of ischemia. Additionally, magnolol $(0.3$ and $1 \mathrm{mg} / \mathrm{kg})$ significantly reduced the accumulation of superoxide anions at the border zones of infarction and reduced oxidative damage in the ischemic brain. This was assessed by measuring the levels of $\mathrm{NO}_{\mathrm{X}}$, malondialdehyde and myeloperoxidase, the ratio of glutathione/oxidized glutathione and the immunoreactions of 8-hydroxy-2'-deoxyguanosine and 4-hydroxynonenal. Thus, magnolol was revealed to
\end{abstract}

Correspondence to: Professor E-Jian Lee, Neurophysiology Laboratory, Department of Surgery, National Cheng Kung University Medical Center and Medical School, 138 Sheng-Li Road, Tainan 70428, Taiwan, R.O.C.

E-mail: ejian@mail.ncku.edu.tw

*Contributed equally

Key words: ischemic stroke, focal cerebral ischemia, oxygenglucose deprivation, neuroprotection, magnolol, superoxide and oxidative damage protect against ischemia-reperfusion brain damage. This may be partly attributed to its antioxidant, radical scavenging and anti-inflammatory effects.

\section{Introduction}

Ischemia induces oxidative stress by inhibiting the consumption of antioxidants and the activity of antioxidant enzymes, and increasing the production of toxic free radicals $(1,2)$. The generation of reactive oxygen species (ROS) and reactive nitrogen species results in disturbed $\mathrm{Ca}^{2+}$ homeostasis and the excitotoxicity of neurons in the ischemic region, which increases the susceptibility of brain tissues to direct or indirect damage by inflammation and apoptosis $(3,4)$. In addition, reperfusion leads to the hydroxylation of nucleotides and peroxidation of phospholipids, which further perpetuates the ischemic damage to neuronal membranous structures and DNA integrity (5). An antioxidant defense mechanism has been suggested to protect the brain from ischemia/reperfusion injury, by either upregulating endogenous antioxidants in 'at risk' tissues, or by reducing the oxidative damage via the scavenging of free radicals overproduced in the ischemic tissues $(3,5,6)$.

Magnolol (5,5'-diallyl-2,2'-dihydroxydiphenyl), a phenolic constituent of magnolia bark, is a potent antioxidant and demonstrates depressive effects on the CNS $(7,8)$. In previous studies, magnolol protected limbs from ischemia-reperfusion damage in a rat model (9), and protected against the brain damage induced by experimental heatstroke (10). In addition, magnolol effectively blocked voltage-dependent $\mathrm{Ca}^{2+}$ channels and reduced cell necrosis in a mixed neuron-astrocyte culture exposed to chemical hypoxia (11-14). Furthermore, magnolol reduced glutamate-induced excitotoxicity in cultured neurons and ameliorated the brain tissue damage caused by permanent middle cerebral artery occlusion up to $4 \mathrm{~h}$ post-insult (15). However, it remains unclear whether magnolol is able to protect the brain against further ischemic insult. Magnolol has been demonstrated to effectively reduced oxidative stress in neuron cultures $(7-9,16,17)$, and may be protective against cerebral ischemic-reperfusion injury in animal models. In particular, it 
is necessary to determine whether magnolol-mediated neuroprotection is provided by the intravenous administration of magnolol, as this mode of administration is most closely associated with the clinical treatment of patients with stroke (18).

In the present study, the neuroprotective effects of magnolol in an oxygen-glucose deprived rat model were characterized. In addition, post-treatment responses and appropriate neuroprotective dosing were explored through the intravenous administration of magnolol to rats subjected to transient focal cerebral ischemia. The underlying mechanisms of action contributing to the neuroprotective properties of magnolol were also explored using in vitro and in vivo assays.

\section{Materials and methods}

Reagents and chemicals. Chemicals, including synthetic ( \pm )- $\alpha$-tocopherol (cat. no. T-3251) and ascorbic acid (cat. no. A4544), were purchased from Sigma-Aldrich (Merck KGaA, Darmstadt, Germany) and the highest grade available was used. Hank's balanced salt solution (HBSS) was used, comprising $8.0 \mathrm{~g} / 1 \mathrm{NaCl}, 0.4 \mathrm{~g} / 1 \mathrm{KCl}, 1.0 \mathrm{~g} / 1$ glucose, $0.06 \mathrm{~g} / 1$ $\mathrm{KH}_{2} \mathrm{PO}_{4}$ and $0.09 \mathrm{~g} / 1 \mathrm{Na}_{2} \mathrm{PO}_{4}-7 \mathrm{H}_{2} \mathrm{O}, \mathrm{pH} 7.1$; glucose-free HBSS was prepared by omitting glucose and adding an additional half-molar amount of $\mathrm{NaCl}$ to adjust the osmolarity $(8.162 \mathrm{~g} / 1 \mathrm{NaCl})$. When used in the present study, magnolol (Wako Pure Chemical Industries, Ltd., Osaka, Japan) was dissolved in dimethylsulfoxide (DMSO) or polyethylene glycol 400 (PEG 400; Merck KGaA).

Lipid peroxidation and radical scavenging assays in vitro. A malondialdehyde (MDA) assay was performed as previously described (19-21). The rat brain tissue was homogenized in $20 \mathrm{mM}$ Tris- $\mathrm{HCl}$ buffer, centrifuged at $1,000 \mathrm{x}$ for $10 \mathrm{~min}$ at $4^{\circ} \mathrm{C}$. To $30 \mu \mathrm{l}$ brain homogenate supernatant was added $10 \mu \mathrm{l}$ vehicle (0.1\% DMSO), magnolol $(0.01 \mu \mathrm{M}-1 \mathrm{mM}), \alpha$-tocopherol (0.1-100 $\mu \mathrm{M})$, ascorbic acid (1-5 mM) or $\beta$-estradiol $(1-150 \mu \mathrm{M})$ and $5 \mu \mathrm{l}$ freshly prepared ferric chloride hexahydrate. The absorbance was measured using a plate reader at $532 \mathrm{~nm}$. The 2,2-diphenyl-1-picrylhydrazyl (DPPH) assay was conducted by adding $100 \mu \mathrm{l}$ freshly prepared DPPH radical solution to $100 \mu \mathrm{l}$ vehicle $(0.1 \%$ DMSO) or magnolol $(0.01 \mu \mathrm{M}-1 \mathrm{mM})$ as previously described (19-21). The absorbance was measured at $517 \mathrm{~nm}$. The 2,2'-azino-bis (3-ethylbenzothiazoline-6-sulfonic acid) diammonium salt (ABTS) assay was conducted by adding $100 \mu \mathrm{l}$ ABTS radical cation solution to $100 \mu \mathrm{l}$ vehicle (0.1\% DMSO) or magnolol (0.01 $\mu \mathrm{M}-1 \mathrm{mM})(19-21)$. The absorbance was measured at $734 \mathrm{~nm}$.

Interleukin (IL)-6, tumor necrosis factor (TNF)-a and nitrate/nitrite $\left(N_{X}\right)$ assay of BV2 and RAW 264.7 cells. Mouse macrophage cell line RAW 264.7 and microglial cell line BV2 (American Type Culture Collection, Manassas, VA, USA) cultured in DMEM (Gibco; Thermo Fisher Scientific, Inc., Waltham, MA, USA) were stimulated with lipopolysaccharide (LPS; Sigma-Aldrich; Merck KGaA), 10 and 100 ng/ml, respectively, based on preliminary dose-response experiments, and co-cultured with PBS, vehicle (0.1\% DMSO) or magnolol (0.1-50 $\mu \mathrm{M})$. Following $6 \mathrm{~h}$ of incubation, the levels of IL-6 and TNF- $\alpha$ in the supernatant were determined using IL-6 (cat. no. DY-406) and TNF- $a$ (cat. no. DY410-05) DuoSet
ELISA kits (R\&D Systems, Inc., Minneapolis, MN, USA) as previously described (19-21). The levels of nitric oxide (NO) in the supernatant were measured using a nitrate/nitrite fluorometric assay kit (cat. no. 780051; Cayman Chemical Company, Ann Arbor, MI, USA) following $16 \mathrm{~h}$ of incubation (19-21).

Organotypic hippocampal slice cultures. Organotypic hippocampal slices were obtained by harvesting $300 \mu \mathrm{m}$-thick hippocampal slices using a motorized NVSLM1 Vibroslice (Campden Instruments Ltd., Loughborough, UK) from 6-7-day-old, neonatal Sprague-Dawley rats weighing 20-30 g. The animals were allowed free access to food and water and housed at $25^{\circ} \mathrm{C}$ and $60 \%$ humidity with a 12-h light/dark cycle (19). The slices were placed on 0.4- $\mu \mathrm{m}$ Millicell culture inserts (EMD Millipore, Billerica, MA, USA) and transferred to $35 \mathrm{~mm}$ Petri dishes. Slices were cultured with organotypic culture medium consisting of $25 \%$ horse serum (Gibco; Thermo Fisher Scientific, Inc.), 25\% HBSS and 50\% minimum essential medium (both MP Biomedicals, LLC, Santa Ana, CA, USA), $5 \mathrm{mg} / \mathrm{ml}$ glucose, $1 \mathrm{mM}$ glutamine, $5 \mathrm{mM} \mathrm{KCl}$ and $1.5 \%$ Fungizone (Gibco; Thermo Fisher Scientific, Inc.) at $37^{\circ} \mathrm{C}$ and the culture medium was refreshed every 3 days.

Oxygen-glucose deprivation (OGD) model in vitro. The OGD model was generated by hypoxia combined with aglycemia, as previously described (19-21). Briefly, the hippocampal slices were cultured for 8-14 days and incubated with medium (1 ml/well glucose-free HBSS, bubbled with $95 \% \mathrm{~N}_{2}$ and $5 \% \mathrm{CO}_{2}$ ) at $37^{\circ} \mathrm{C}$ for $20 \mathrm{~min}$ prior to OGD. The culture dishes were incubated in an anaerobic chamber at $37^{\circ} \mathrm{C}$ with $95 \%$ $\mathrm{N}_{2}$ and $5 \% \mathrm{CO}_{2}$ for $120 \mathrm{~min}$. A normal control group was also established, in which the hippocampal slices were incubated in $\mathrm{HBSS}$ with $95 \% \mathrm{O}_{2}$ and $5 \% \mathrm{CO}_{2}$ at $37^{\circ} \mathrm{C}$. Replenishment of the cells was induced by replacing the medium and incubating the dishes under normoxic conditions for a further $24 \mathrm{~h}$. To evaluate cell damage, $5 \mu \mathrm{g} / \mathrm{ml}$ propidium iodide (PI) was incubated with the culture at $37^{\circ} \mathrm{C}$ for $20 \mathrm{~min}$, and the absorbance was measured at $630 \mathrm{~nm}$ and analyzed using Image Pro Plus software, version 5.1 (Media Cybernetics, Inc., Rockville, MD, USA) with a digital CoolSNAP-Pro ${ }_{\text {cf }}$ camera (Media Cybernetics, Inc.) and an IX71 epi-fluorescence inverted microscope (Olympus Corporation, Tokyo, Japan). The fluorescence intensity $(\mathrm{Ft})$ of the slices was obtained from three different fields of the slices. Regions without the slices were used as the background intensity (F0). At $48 \mathrm{~h}$ after OGD, culture slices were incubated with $10 \mathrm{mM}$ glutamate to determine the final PI fluorescence (Ffin). The PI uptake, as an indicator of cell death, was subsequently obtained from the following equation: PI $(\%)=($ Ft-F0) $/($ Ffin-F0) x100 (19). An OGD duration of 120 min induces $70 \%$ of the maximal PI-uptake in CA1 pyramidal neurons (19). Experimental treatment groups were established as follows: i) Pre-treatment group, treated with magnolol (10 or $100 \mu \mathrm{M})$ or vehicle $(0.1 \%$ DMSO) for $1 \mathrm{~h}$ prior to the OGD period, with no additions to the medium during the following $24 \mathrm{~h}$; ii) post-treatment group, treated with magnolol $(100 \mu \mathrm{M})$ or vehicle $(0.1 \%$ DMSO) at 2,4 or $6 \mathrm{~h}$ post OGD.

Animal anesthesia and monitoring. Male Sprague-Dawley rats ( $\mathrm{n}=120 ; 8$ weeks old, weighing 260-300 g), were obtained from the National Cheng Kung University Animal Center 
(Tainan, Taiwan). The animals were allowed free access to food and water and housed at $25^{\circ} \mathrm{C}, 60 \%$ humidity on a $12-\mathrm{h}$ light/dark cycle. Rats were anesthetized with halothane, 3-4\% for induction and 1-2\% for maintenance. The right femoral artery was cannulated for the measurements of arterial blood gases, hematocrit, glucose, heart rate and blood pressure. During surgery the core temperature was maintained at $37.0 \pm 0.5^{\circ} \mathrm{C}$ by the use of a heating blanket (Harvard Apparatus, Holliston, MA, USA).

All procedures within the present study were performed in accordance with the recommendations of the Guide for the Care and Use of Laboratory Animals of the National Institutes of Health (eighth edition, 2011). The protocol for the present study was approved by the Committee on the Ethics of Animal Experiments of the National Cheng Kung University Hospital (permit no. 102249; Tainan, Taiwan).

Experimental model. A stable ischemia animal model was generated as previously described, by the occlusion of the right proximal middle cerebral artery (MCA) with an intra-arterial suture for $90 \mathrm{~min}$ (19-21). The local cortical cerebral perfusion (local cerebral blood flow, LCBF) was measured using Laserflo BMP2 Laser-Doppler flowmetry (Vasamed Inc., Eden Prairie, MN, USA) to ensure the quality of the ischemia and reperfusion induction (19-23).

The investigators were blinded to the treatment paradigms and the rats were randomly separated into Magnolol and vehicle groups. In a first series of experiments, magnolol $(0.01,0.1,1$ or $5 \mathrm{mg} / \mathrm{kg} ; \mathrm{n}=10,10,13$ and 9 , respectively) or vehicle (PEG 400, $10 \mathrm{ml} / \mathrm{kg} ; \mathrm{n}=12$ ) was administered intravenously (i.v.) $30 \mathrm{~min}$ prior to the onset of ischemia. Rats were euthanized $72 \mathrm{~h}$ following the onset of ischemia and their brains examined using standard 2,3,5-triphenyltetrazolium chloride (TTC)-stained histological sections. In a second series of experiments, rats were treated with magnolol ( $1 \mathrm{mg} / \mathrm{kg}$, i.v.; $\mathrm{n}=10$ ) or vehicle (i.v.; $\mathrm{n}=10) 2 \mathrm{~h}$ after the onset of ischemia. Following ischemia for $72 \mathrm{~h}$, rats were euthanized using histological sections and immunofluorescence staining.

Another set of rats were treated with magnolol $(0.01,0.3$ or $1 \mathrm{mg} / \mathrm{kg}$, i.v.; $\mathrm{n}=8$ per group) or vehicle (PEG 400; $10 \mathrm{ml} / \mathrm{kg}$, i.v.; $\mathrm{n}=8$ ) at $2 \mathrm{~h}$ following the onset of ischemia, and euthanized at $24 \mathrm{~h}$ post-insult, to assess the levels of myeloperoxidase (MPO), malondialdehyde (MDA), $\mathrm{NO}_{\mathrm{X}}$ and the ratio of reduced glutathione/oxidized glutathione (GSH/GSSG) in the brain tissue. The $\mathrm{NO}_{\mathrm{X}}$ level was accessed using the aforementioned nitrate/nitrite fluorometric assay kit.

Lipid peroxidation and MPO activity in vivo. MDA and MPO activity in brain tissue were determined as previously described (19,20). Absorbance was measured using a plate reader at 532 and $492 \mathrm{~nm}$, respectively.

Histology and immunofluorescence of 8-hydroxy-2'deoxyguanosine (8-OHdG) and 4-hydroxynonenal (4-HNE). Rat brains were sectioned coronally as previously described $(20,22,23)$, into $40-\mu \mathrm{m}$ sections at 1 -mm intervals from the bregma AP (4.2 to $-6.8 \mathrm{~mm}$ ) on a cryostat. Two sets of sections were used for the immunofluorescence staining of 4-HNE and 8-OHdG. The expression of 4-HNE and 8-OHdG was used to identify membranous lipid peroxidation and
DNA damage, respectively (5). Sections were washed in PBS (Molecular Probes; Thermo Fisher Scientific, Inc.) and incubated in $3 \% \mathrm{H}_{2} \mathrm{O}_{2}$ with $50 \%$ methanol/PBS at room temperature for $30 \mathrm{~min}$, then placed in PBS containing $0.3 \%$ Triton X-100 and blocked with $1 \%$ normal sheep serum (Millipore, Merck $\mathrm{KGaA}$ ) at room temperature for $30 \mathrm{~min}$. Sections were incubated with monoclonal antibodies directed against 8-OHdG (1:750; MOG-100P) and 4-HNE (1:1,000; MHN-100P; both JaICA, Fukuroi, Japan) overnight at $4^{\circ} \mathrm{C}$. Goat anti-rabbit IgG secondary antibodies conjugated with biotin (1:100; cat. no. 111-065-144; Jackson ImmunoResearch Laboratories, Inc., West Grove, PA, USA) were subsequently incubated with the sections at room temperature for $1 \mathrm{~h}$, followed by fluorescein (DTAF)-conjugated streptavidin (1:150; cat. no. 016-010-084; Jackson ImmunoResearch Laboratories, Inc.). Immunopositive cells were traced and measured using a Zeiss Axioskop 2 Mot microscope (Zeiss AG, Oberkochen, Germany) equipped with a digital CoolSNAP-Pro ${ }_{c f}$ camera and computerized image analyzer (MCID Elite 6.01.4; Imaging Research Inc., St Catharines, ON, Canada). Fluorescence was measured at 450-490 $\mathrm{nm}$ and emission >515 $\mathrm{nm}$ for DTAF detection.

For the assessment of ischemic damage to the neuronal perikarya, another set of sections was stained with $0.5 \%$ cresyl violet. Using light microscopy (Zeiss Axioskop 2 Mot microscope), the areas of neuronal perikarya displaying typical morphologic features of ischemic damage were evaluated.

Detection of free radicals using in situ dihydroethidium (DHE). Sections $40 \mu \mathrm{m}$ in thickness were stained with $5 \mathrm{mM}$ $\mathrm{DHE}$ at $37^{\circ} \mathrm{C}$ for $30 \mathrm{~min}$ as previously described (5), and subsequently incubated with DAPI $(2 \mu \mathrm{M})$ in PBS at room temperature for $15 \mathrm{sec}$ in a dark chamber. Section fluorescence was evaluated at an excitation wavelength of 510-550 $\mathrm{nm}$ and emission wavelength of $>580 \mathrm{~nm}$ for oxidized DHE (HEt) detection, and at excitation and emission wavelengths of 365 and $>420 \mathrm{~nm}$ for DAPI detection. The density and intensity of the HEt in the ischemic brain tissue was compared between the magnolol-treated animals and the controls.

Determination of reduced GSH/GSSG. In the ischemic brain tissues, the total GSH and GSSG levels were determined as previously described by Anderson (24). Briefly, GSH was oxidized by $5,5^{\prime}$-dithio-bis(2-nitrobenzoic acid) to generate GSSG with stoichiometric formation of 5-thio-2-nitrobenzoic acid (TNB). GSSG was subsequently reduced to GSH by the action of the highly specific glutathione reductase and NADPH. The rate of TNB formation was measured at $412 \mathrm{~nm}$ and was proportional to the sum of GSH and GSSG. For GSSG determination, 2-vinylpyridine was used to destroy the reduced form of $\mathrm{GSH}$, followed by the same procedure as the GSH assay.

Euthanasia and quantification of ischemic damage. Animals were euthanized at $72 \mathrm{~h}$ following the onset of ischemia. A rat brain matrix (RBM 4000C; ASI Instruments Inc., Warren, MI, USA) was used to cut 2-mm coronal sections. These sections were stained using TTC at room temperature for $30 \mathrm{~min}$ in a dark chamber (15). In the delayed treatment paradigm, ischemic brain damage was measured using TTC and cresyl violet-stained brain sections as previously described $(20,22,23)$. Coronal section images were captured using a DXC-390 
Table I. Antioxidant and radical scavenging potency $\left(\mathrm{IC}_{50}\right)$ of magnolol and reference antioxidant compounds.

\begin{tabular}{|c|c|c|c|}
\hline Substance & $\begin{array}{c}\text { Inhibition of lipid peroxidation } \\
\text { induced by } \mathrm{Fe}^{3+}(10 \mathrm{mM}) \\
\text { in rat brain homogenate }(\mu \mathrm{M})\end{array}$ & $\begin{array}{c}\text { DPPH radical } \\
\text { scavenging assay }\end{array}$ & $\begin{array}{c}\text { ABTS radical } \\
\text { scavenging assay }(\mu \mathrm{M})\end{array}$ \\
\hline Magnolol & $0.8 \pm 2.8$ & $531.9 \pm 1.0 \mu \mathrm{M}$ & $22.3 \pm 0.5$ \\
\hline$\alpha$-tocopherol & $45.9 \pm 7.4$ & $84.4 \pm 2.8 \mu \mathrm{M}$ & $35.3 \pm 7.3$ \\
\hline Ascorbic acid & $2,770.0 \pm 110.0$ & $47.5 \pm 2.4 \mu \mathrm{M}$ & $31.7 \pm 6.8$ \\
\hline$\beta$-estradiol & $65.6 \pm 7.9$ & $202.4 \pm 18.0 \mathrm{mM}$ & $16.9 \pm 3.2$ \\
\hline
\end{tabular}

The $\mathrm{IC}_{50}$ value was defined as the concentration of compound required to reduce the absorbance to half of the initial value in $30 \mathrm{~min}$ at $37^{\circ} \mathrm{C}$. Data are expressed as the mean \pm standard deviation $(\mathrm{n}=8)$. DPPH, 2,2-diphenyl-1-picrylhydrazyl; ABTS, 2,2'-azino-bis(3-ethylbenzothiazoline-6-sulfonic acid.

Table II. Pre-treatment with magnolol improves sensorimotor neurobehavioral scores following cerebral ischemia-reperfusion.

\begin{tabular}{|c|c|c|c|}
\hline \multirow[b]{2}{*}{ Treatment } & \multicolumn{3}{|c|}{ Neurologic behavioral score } \\
\hline & Motor & Sensory & 28-point clinical scale \\
\hline \multicolumn{4}{|c|}{ Day 1 post ischemia } \\
\hline Vehicle & $2(1.8-2.2)$ & $4(3.9-4.1)$ & $18.5(17.4-19.6)$ \\
\hline \multicolumn{4}{|c|}{ Magnolol (mg/kg) } \\
\hline 0.01 & $1(0.7-1.3)^{\mathrm{a}}$ & $2(1.4-2.6)^{\mathrm{a}}$ & $9.5(7.5-11.5)^{\mathrm{a}}$ \\
\hline 0.1 & $1(0.7-1.3)^{\mathrm{a}}$ & $2(1.4-2.6)^{\mathrm{a}}$ & $9.5(8.2-10.8)^{\mathrm{a}}$ \\
\hline 1.0 & $1(0.8-1.2)^{\mathrm{a}}$ & $2(1.6-2.4)^{\mathrm{a}}$ & $10(8.7-11.3)^{\mathrm{a}}$ \\
\hline 5 & $1(0.7-1.3)^{\mathrm{a}}$ & $2.5(2.0-3.0)^{\mathrm{a}}$ & $9(7.6-10.4)^{\mathrm{a}}$ \\
\hline \multicolumn{4}{|c|}{ Day 3 post ischemia } \\
\hline Vehicle & $2(1.7-2.3)$ & $4(3.5-4.5)$ & $18(16.5-19.5)$ \\
\hline \multicolumn{4}{|c|}{ Magnolol (mg/kg) } \\
\hline 0.01 & $1(0.7-1.3)^{\mathrm{a}}$ & $2(1.4-2.6)^{\mathrm{a}}$ & $9(7.7-10.3)^{\mathrm{a}}$ \\
\hline 0.1 & $1(0.7-1.3)^{\mathrm{a}}$ & $2(1.4-2.6)^{\mathrm{a}}$ & $10(8.6-11.4)^{\mathrm{a}}$ \\
\hline 1 & $1.5(1.3-1.7)^{\mathrm{a}}$ & $2(1.6-2.4)^{\mathrm{a}}$ & $11(9.9-12.1)^{\mathrm{a}}$ \\
\hline 5 & $2(1.7-2.3)^{\mathrm{a}}$ & $2(1.3-2.7)^{\mathrm{a}}$ & $9(7.5-10.5)^{\mathrm{a}}$ \\
\hline
\end{tabular}

3-CCD color camera (Sony, Tokyo, Japan) equipped with a Micro-Nikon $55 \mathrm{~mm}$ f2.8 lens. Areas of ischemic damage were analyzed using a computerized image analyzer (MCID Elite 6.01.4). The cerebral ischemic infarction volume was expressed as a percentage of the contralateral hemisphere volume as previously described $(20,22,23)$. Additionally, individual striatal and cortical infarct sizes were calculated.

Sections were obtained between the Bregma AP-0.22 and $-0.78 \mathrm{~mm}$. Six non-overlapping regions $\left(500 \times 400 \mu \mathrm{m}^{2}\right)$ were randomly selected for cell counting of the surviving neurons in the ischemic brain, as previously described $(20,22,23)$. Surviving neurons were expressed as the mean number of viable neurons per $\mathrm{mm}^{2}$.

Neurobehavioral testing. Neurologic evaluation was conducted 1 and 3 days following stroke induction by a qualified observer unaware of the treatment protocol. Two different neurologic grading systems were used in the present study. The first was a sensorimotor grading scale with five categories (0-4) for forward and sideways visual placing tests of the affected forelimb, and five categories (0-4) for motor outcome, which is a modification of previously described methods $(20,22,23,25)$. The second was a neurobehavioral grading scale of 0 to 28 for rodents, as previously described (26).

Statistical analysis. Data are expressed as the mean \pm standard deviation and differences between groups were evaluated using an unpaired Student's t-test or one-way analysis of variance with Fisher's protected least significant difference post hoc test. To evaluate the response in changing conditions a paired Student's t-test was used. The data for neurobehavioral testing are expressed as the median (95\% confidence interval) 

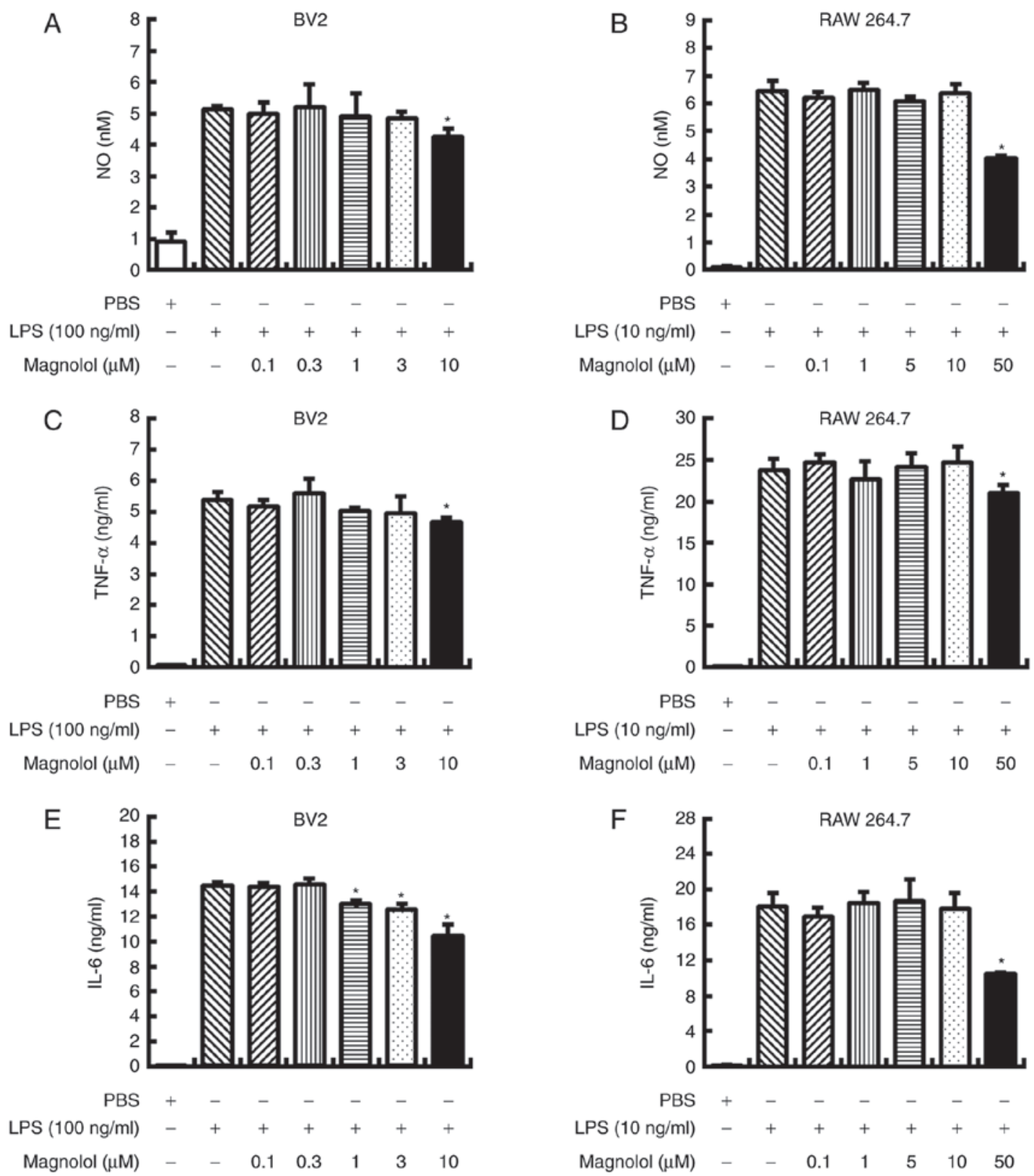

Figure 1. Effect of magnolol on LPS-stimulated RAW 264.7 and BV2 cells. RAW 264.7 and BV2 cells were stimulated with LPS (10 and $100 \mathrm{ng} / \mathrm{ml}$, respectively) and treated with increasing concentrations of magnolol (0.1-50 $\mu \mathrm{M})$. The levels of NO in (A) BV2 and (B) RAW 264.7 cells were measured using a fluorometric assay kit. The levels of TNF-a were also measured in (C) BV2 and (D) RAW 264.7 cells, and the levels of IL-6 in (E) BV2 and (F) RAW 264.7 cells were measured using ELISA kits. All measurements were taken at $6 \mathrm{~h}$ following stimulation with LPS. $\mathrm{P}<0.05 \mathrm{vs.} \mathrm{LPS} \mathrm{only} \mathrm{group.} \mathrm{NO,} \mathrm{nitric} \mathrm{oxide;} \mathrm{TNF,}$ tumor necrosis factor; IL, interleukin; LPS, lipopolysaccharide.

and were evaluated using a nonparametric test for independent groups, including the Kruskal-Wallis and Mann-Whitney U tests. SPSS software, version 17.0 (SPSS, Inc., Chicago, IL, USA) was used to conduct the analysis. $\mathrm{P}<0.05$ was considered to indicate a statistically significant difference.

\section{Results}

Radical scavenging and antioxidant assays. Magnolol attenuated $\mathrm{Fe}^{3+}$-induced lipid peroxidation in brain tissue homogenate with an $\mathrm{IC}_{50}$ value of $0.8 \pm 2.8 \mu \mathrm{M}$ (Table I), which was lower than the $\mathrm{IC}_{50}$ values for $\alpha$-tocopherol, ascorbic acid and $\beta$-estradiol $(45.9 \pm 7.4,2,770.0 \pm 110.0$ and $65.6 \pm 7.9 \mu \mathrm{M}$, respectively). However, in the DPPH radical scavenging assay, the $\mathrm{IC}_{50}$ value of magnolol was $531.9 \pm 1.0 \mu \mathrm{M}$, which was greater than the $\mathrm{IC}_{50}$ value for a-tocopherol and ascorbic acid (84.4 \pm 2.8 and $47.5 \pm 2.4 \mu \mathrm{M}$, respectively), but lower than that for $\beta$-estradiol $(202.4 \pm 18.0 \mathrm{mM})$. In the ABTS radical cation scavenging assay, the $\mathrm{IC}_{50}$ value of magnolol was $22.3 \pm 0.5 \mu \mathrm{M}$, which was similar to the $\mathrm{IC}_{50}$ values of the antioxidants $\alpha$-tocopherol, $\beta$-estradiol and ascorbic acid $(35.3 \pm 7.3,16.9 \pm 3.2$ and $31.7 \pm 6.8 \mu \mathrm{M}$, respectively).

LPS stimulates proinflammatory cytokines and NO production in vitro. Magnolol significantly reduced NO production when applied to LPS-stimulated BV2 and RAW 264.7 cells at concentrations of 10 and $50 \mu \mathrm{M}$, respectively $(\mathrm{P}<0.05$; Fig. 1A and B). Similarly, magnolol significantly reduced TNF- $\alpha$ 
A
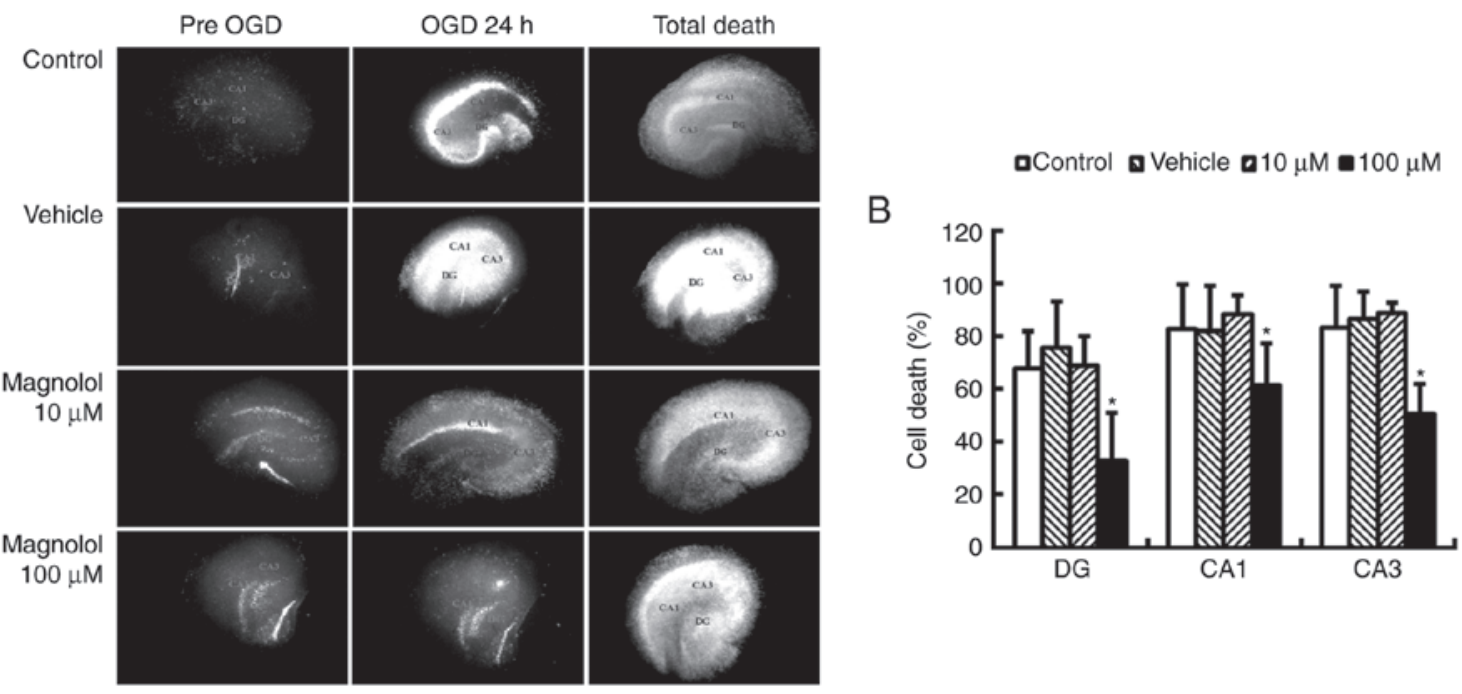

C
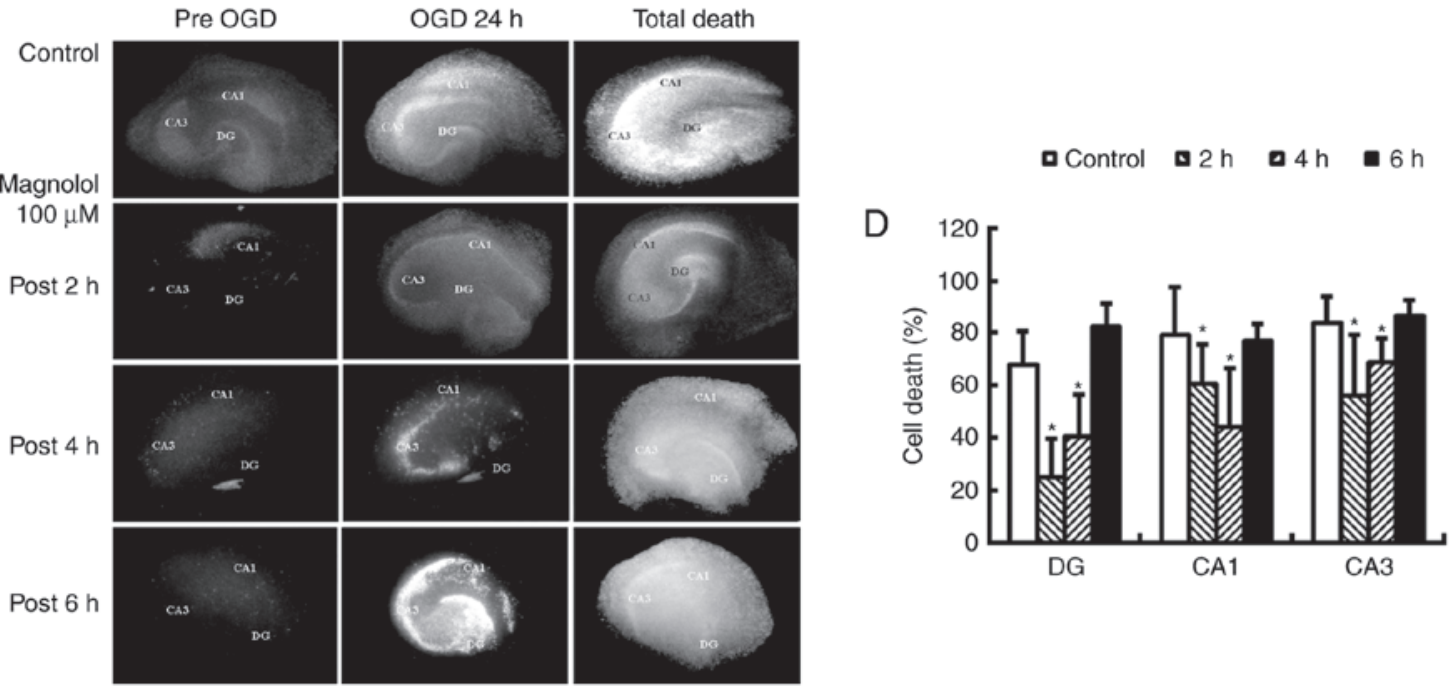

Figure 2. Magnolol reduces PI uptake in hippocampal slice cultures following OGD damage. (A) Images of hippocampal slice cultures that were treated with magnolol prior to OGD. (B) PI uptake in the hippocampal slice cultures was quantified and examined according to the subsection of the brain to determine the percentage of dead cells. (C) Images of hippocampal slice cultures that were treatment with magnolol post-OGD. (D) PI uptake in the hippocampal slice cultures was quantified and examined according to the subsection of the brain. " $\mathrm{P}<0.05$ vs. the control. OGD, oxygen-glucose deprivation; total death, treated with $10 \mathrm{mM}$ glutamate at $48 \mathrm{~h}$ post-OGD; PI, propidium iodide.

production in LPS-stimulated BV2 and RAW 264.7 cells when administered at concentrations of 10 and $50 \mu \mathrm{M}$, respectively $(\mathrm{P}<0.05$; Fig. 1C and D). Additionally, magnolol significantly inhibited IL-6 production when administered at 1-10 $\mu \mathrm{M}$ in LPS-stimulated BV2 cells and $50 \mu \mathrm{M}$ in LPS-stimulated RAW 264.7 cells ( $\mathrm{P}<0.05$; Fig. 1E and F).

OGD of hippocampal slice cultures. No significant differences were identified in the PI uptake in cultures treated with 1-100 $\mu \mathrm{M}$ magnolol compared with the control cultures (data not shown). Pre-treatment with magnolol at $100 \mu \mathrm{M} 1 \mathrm{~h}$ prior to OGD led to a significant reduction in cell death at $24 \mathrm{~h}$ compared with the control ( $\mathrm{P}<0.05$; Fig. $2 \mathrm{~A}$ and $\mathrm{B})$. The PI uptake was reduced by $25.0,41.6$ and $56.6 \%$ in the CA1, CA3 and DA regions, respectively compared with the OGD control. Treatment with magnolol $(100 \mu \mathrm{M})$ at 2 or $4 \mathrm{~h}$ following the onset of OGD significantly reduced the OGD-induced increases in PI uptake in the CA1, CA3 and DA sub-regions of the brain compared with the control $(\mathrm{P}<0.05$; Fig. $2 \mathrm{C}$ and $\mathrm{D})$.
The PI uptake was reduced by $23.8-44.1 \%$ in CA1, 17.7-33.0\% in CA3 and 40.0-62.9\% in DA.

Transient focal cerebral ischemia in rats. A total of 7 animals (6.0\%) died during the course of the experiment and were excluded. Of these animals, $3(7.9 \%)$ were in the vehicle-injected group and 4 (5.1\%) were in the magnolol-treated group. As described previously $(20,21)$, animals subjected to transient MCA occlusion invariably exhibit spontaneous hyperthermia. The post-insult core temperatures and LCBF were not notably changed by the intravenous administration of magnolol at $0.01-5 \mathrm{mg} / \mathrm{kg}$ (data not shown). The physiological parameters blood hematocrit, arterial blood pressure, heart rate and glucose of the experimental animals were not notably different from those of the control animals over the course of the experiment (data not shown).

Neuroprotectiveactionsofmagnololagainstischemic-reperfusion insult in vivo. Pre-treatment with magnolol at doses of $0.01,0.1$ 
A
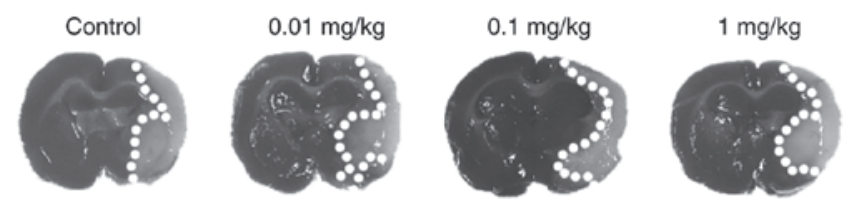

$5 \mathrm{mg} / \mathrm{kg}$
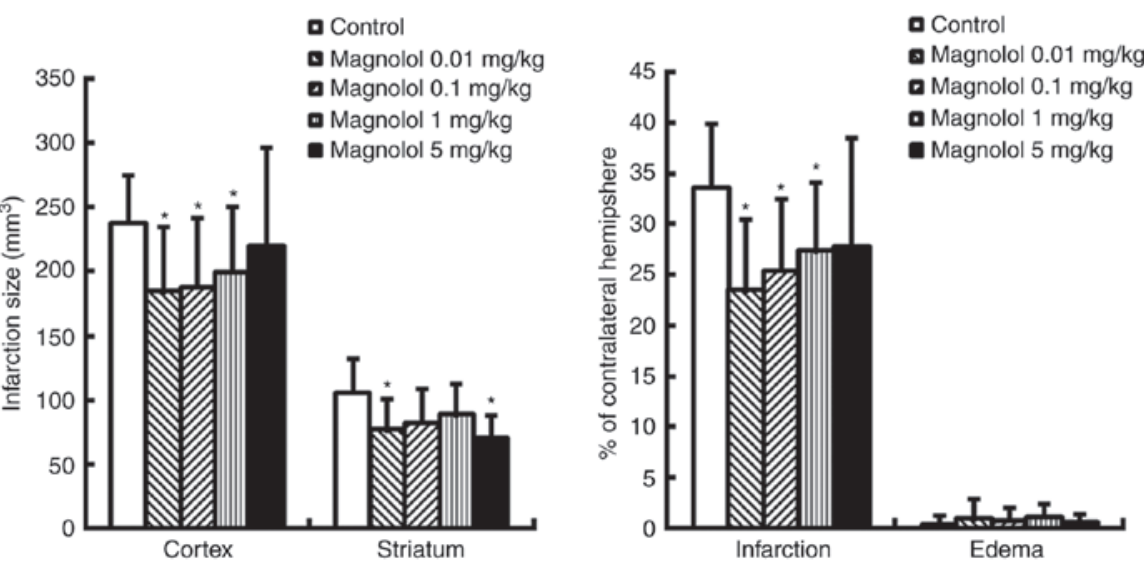

B
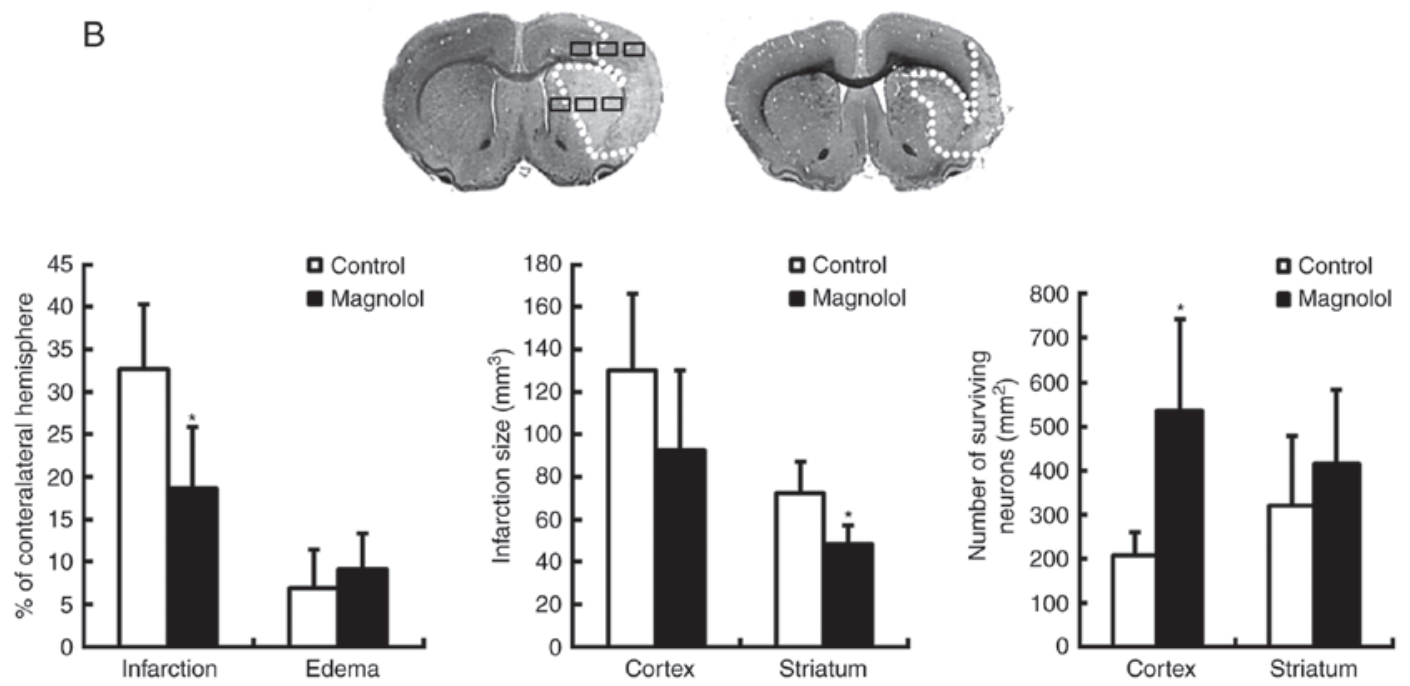

Figure 3. Magnolol treatment reduces cerebral infarction and increases the number of surviving neurons. (A) Coronal sections of animals treated with PEG 400 (vehicle, control) or magnolol $(0.01,0.1,1$, or $5 \mathrm{mg} / \mathrm{kg}$ ) $30 \mathrm{~min}$ prior to the onset of middle cerebral artery occlusion were obtained $72 \mathrm{~h}$ following the onset of ischemia and stained with 2,3,5-triphenytetrazolium chloride. The infarction (pale region) was observed in the striatum and cortex, and the infarction volume was significantly decreased in the magnolol-treated animals. (B) Coronal sections from animals treated with PEG 400 (vehicle) or magnolol (1 mg/kg) at $2 \mathrm{~h}$ following the onset of ischemia were stained with cresyl violet at $72 \mathrm{~h}$. In the cortex and striatum, 6 random non-overlapping regions $\left(500 \mathrm{x} 400 \mu \mathrm{m}^{2}\right)$ were selected in which to count the surviving neurons. In the delayed treatment paradigm, magnolol $(1 \mathrm{mg} / \mathrm{kg})$ significantly attenuated the infarction volume and significantly increased the number of surviving neurons in the cortex compared with the vehicle group. "P<0.05 vs. the vehicle group. PEG 400 , polyethylene glycol 400 .

or $1 \mathrm{mg} / \mathrm{kg} 30 \mathrm{~min}$ prior to ischemia, significantly reduced the infarction size in the cortex compared with the control $(\mathrm{P}<0.05$; Fig. 3A). Treatment with magnolol at $0.01,0.1$ and $1 \mathrm{mg} / \mathrm{kg}$ reduced the infarction volume in the cortex by 30.2, 24.3 and $22.7 \%$, respectively, compared with the control. Treatment with magnolol $(0.01-5 \mathrm{mg} / \mathrm{kg})$ also significantly improved the sensory neurologic scores at $72 \mathrm{~h}$ post ischemic injury compared with those in the vehicle group $(\mathrm{P}<0.05$; Table II).

When magnolol $(1 \mathrm{mg} / \mathrm{kg})$ was administered at $2 \mathrm{~h}$ post ischemic onset, the infarction volume in the striatum as a percentage of the volume of the contralateral hemisphere was significantly reduced by $43.3 \%$ at $72 \mathrm{~h}$ post ischemia compared with the control $(\mathrm{P}<0.05$; Fig. $3 \mathrm{~B})$. The infarction volume in the striatum was reduced by $31.2 \%$, and a significant improvement in the number of surviving neurons in the penumbral cortical area was also observed (both $\mathrm{P}<0.05$; Fig. 3B). In addition, treatment with magnolol $2 \mathrm{~h}$ post ischemic onset significantly increased the neurologic and sensorimotor scores determined 3 days following the onset of ischemia, compared with the vehicle group $(\mathrm{P}<0.05$; Table III).

MPO and $N O_{X}$ levels in the reperfused brain. In the control group, notably increased levels of MPO and $\mathrm{NO}_{\mathrm{X}}$ activity were measure in the brain at $24 \mathrm{~h}$ following the onset of ischemia, which is indicative of neutrophil infiltration (Fig. 4A and B). Treatment with magnolol $(0.3-1 \mathrm{mg} / \mathrm{kg}) 2 \mathrm{~h}$ following the onset of ischemia resulted in a significant reduction in the levels of MPO and $\mathrm{NO}_{\mathrm{X}}$ at $24 \mathrm{~h}$ compared with the control 
A

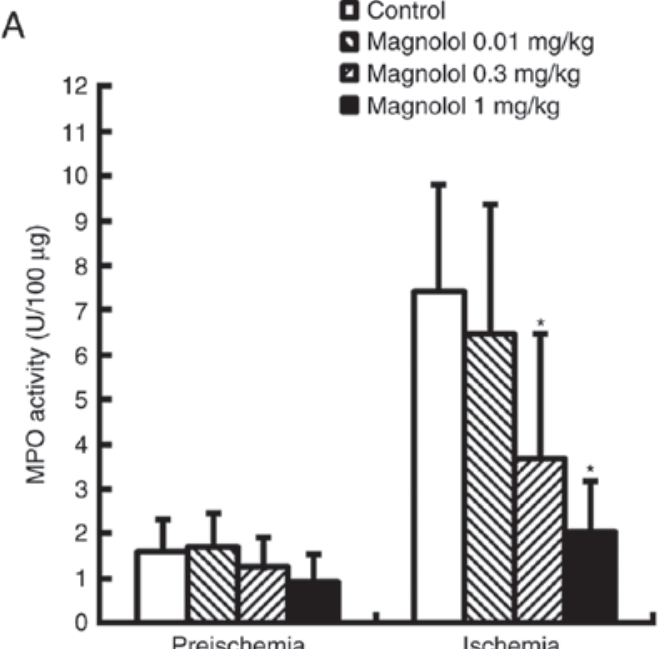

Preischemia

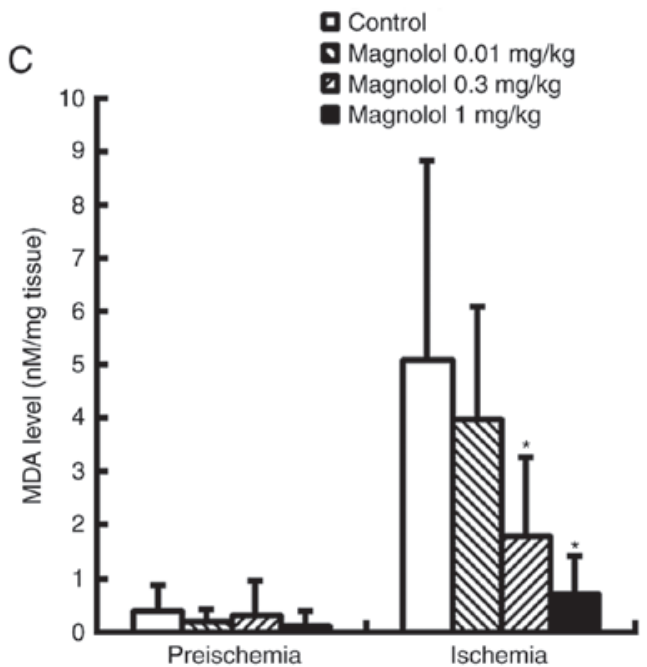

B

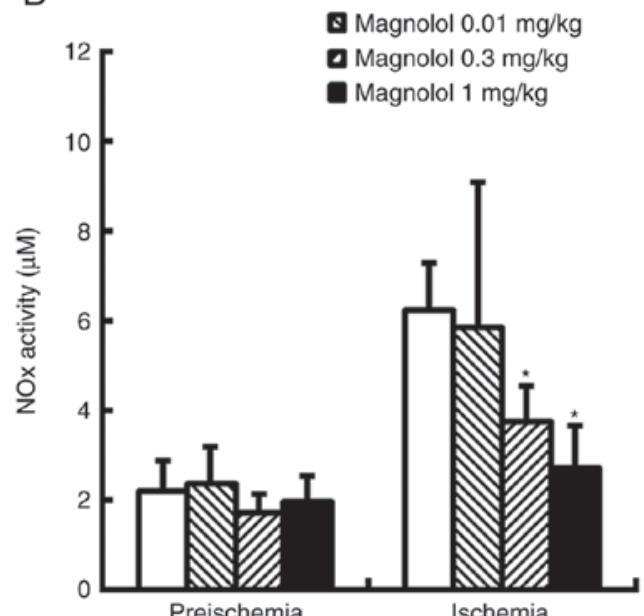

Preischemia

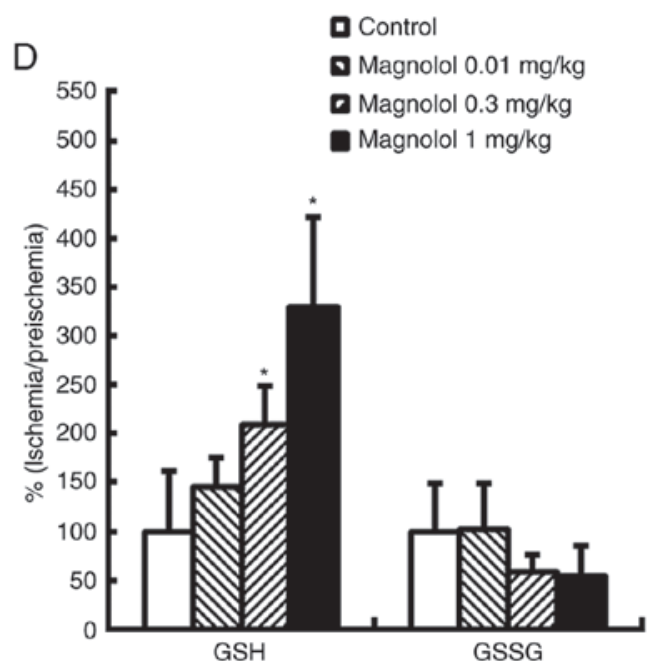

Figure 4. Magnolol attenuates NOx and MPO activity, reduces lipid peroxidation and increases GSH in the ischemic brain. An MDA assay was performed to assess lipid peroxidation in the ischemic brain. Magnolol significantly reduced the (A) MPO and (B) NOx activity and (C) MDA levels and significantly increased (D) GSH activity, compared with the ischemic control. No significant changes were observed in the GSSG value. ${ }^{*}<0.05$ vs. the vehicle group. $\mathrm{NO}_{\mathrm{X}}$, nitrite/nitrate; MPO, myeloperoxidase; MDA, malondialdehyde; GSH, reduced glutathione; GSSG, glutathione disulfide.

Table III. Delayed treatment with magnolol improves sensorimotor neurobehavioral scores following cerebral ischemia-reperfusion.

\begin{tabular}{|c|c|c|c|}
\hline \multirow[b]{2}{*}{ Treatment } & \multicolumn{3}{|c|}{ Neurologic behavioral score } \\
\hline & Motor & Sensory & 28-point clinical scale \\
\hline \multicolumn{4}{|l|}{ Day 1 post ischemia } \\
\hline Vehicle & $3(2.6-3.3)$ & $4(3.7-4.2)$ & $20(19.1-20.9)$ \\
\hline Magnolol (1 mg/kg) & $1(0.6-1.4)^{\mathrm{a}}$ & $2(1.5-2.5)^{\mathrm{a}}$ & $9.5(8.4-10.6)^{\mathrm{a}}$ \\
\hline \multicolumn{4}{|l|}{ Day 3 post ischemia } \\
\hline Vehicle & $3(2.8-3.2)$ & $4(3.8-4.2)$ & $20(19.6-20.4)$ \\
\hline Magnolol (1 mg/kg) & $1.5(1.1-1.9)^{\mathrm{a}}$ & $2(1.2-2.8)^{\mathrm{a}}$ & $11(9.1-12.9)^{\mathrm{a}}$ \\
\hline
\end{tabular}

group $(\mathrm{P}<0.05)$. MPO and $\mathrm{NO}_{\mathrm{X}}$ were reduced by $50.4-72.5 \%$ and $40.0-56.7 \%$ respectively. No significant differences were identified in MPO and $\mathrm{NO}_{\mathrm{x}}$ activity following treatment with magnolol at a dosage of $0.01 \mathrm{mg} / \mathrm{kg}$. 
A

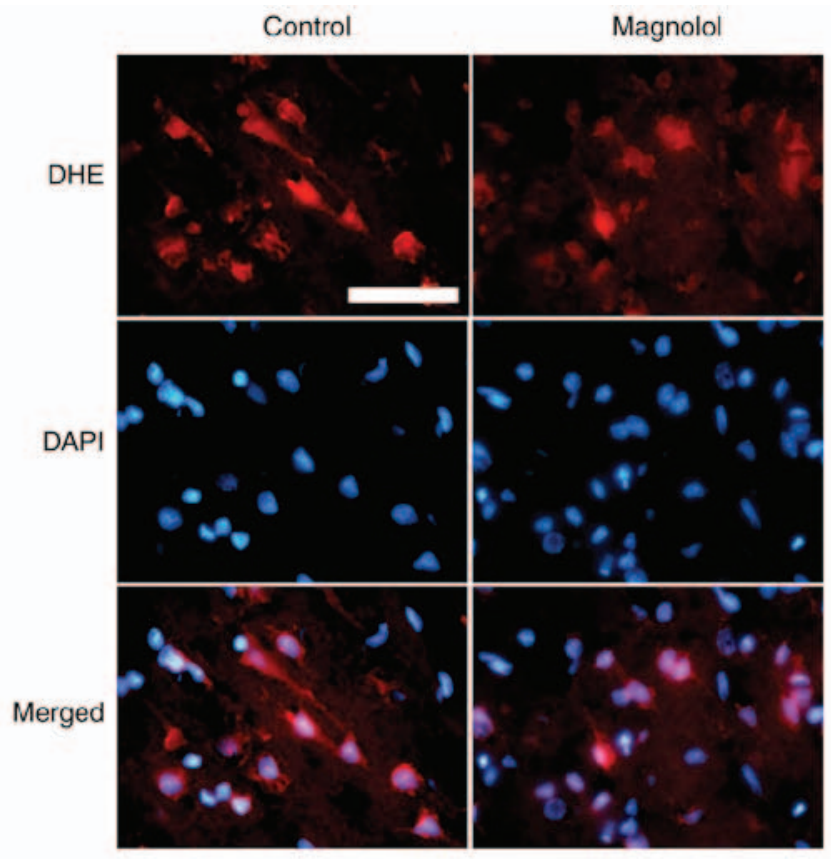

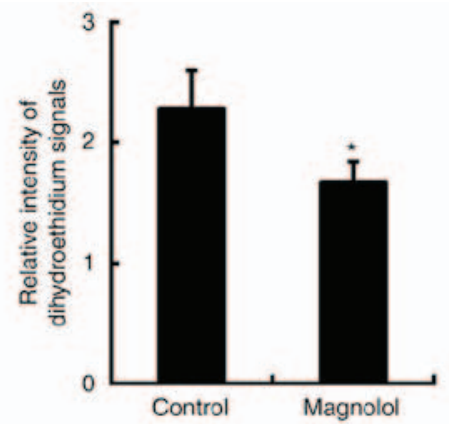

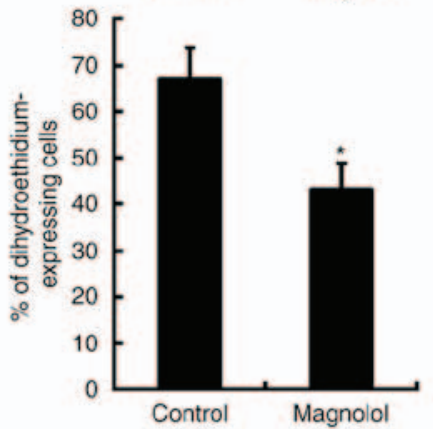

B

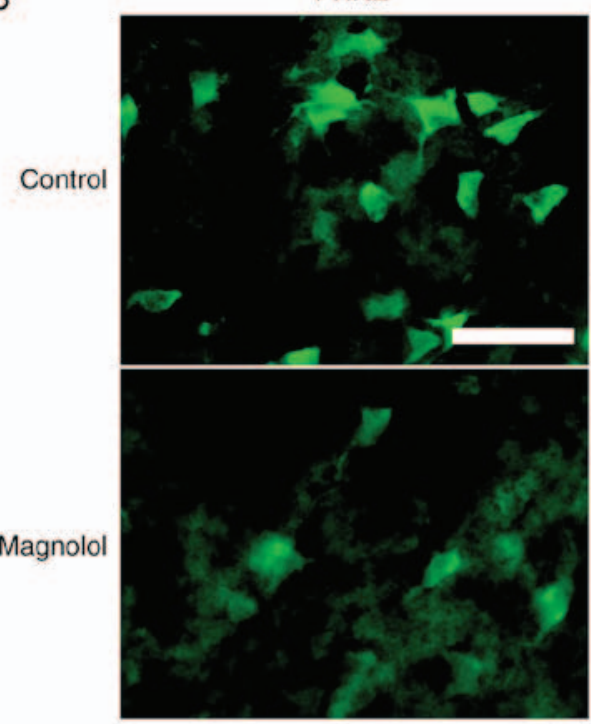

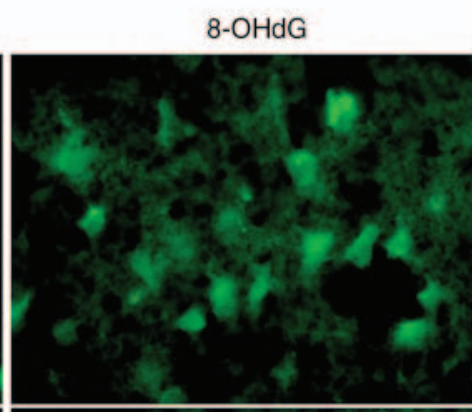

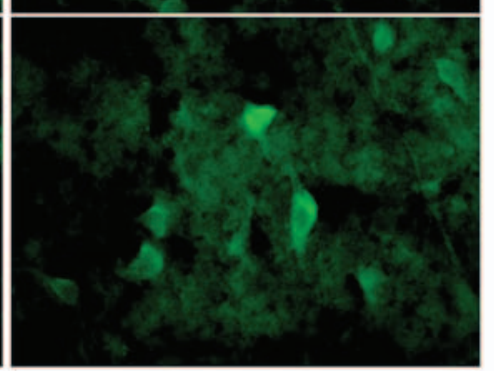

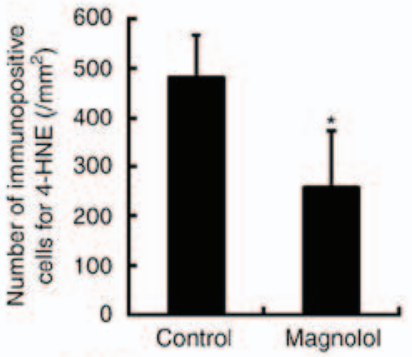

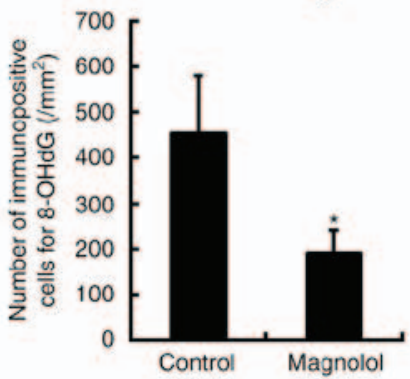

Figure 5. Magnolol decreased the in situ accumulation of superoxide and reduced 8-OHdG immunoreactivity and 4-HNE in the ischemic brain when administered at a dose of $1 \mathrm{mg} / \mathrm{kg}$ at $2 \mathrm{~h}$ following the onset of ischemia. (A) At $72 \mathrm{~h}$ post-ischemic onset, strong signals for oxidized DHE (red) signals were observed in the cortex of the vehicle-treated control animals. In the magnolol-treated animals, the oxidized DHE signal expression and intensity was significantly decreased compared with the control. (B) Oxidative DNA damage was evaluated by 8-OHdG immunoreactivity and lipid peroxidation was evaluated by 4-HNE immunoreactivity. The numbers of 8-OHdG and 4-HNE immunopositive cells were significantly attenuated in the magnolol-treated group, compared with the controls. "P<0.05 vs. the vehicle group. Scale bar, $50 \mu \mathrm{m}$. 8-OHdG, 8-hydroxy-2'-deoxyguanosine; DHE, dihydroethidium; 4-HNE, 4-hydroxynonenal.

Lipid peroxidation and the GSH/GSSG ratio are reduced in the reperfused brain. Ischemic-reperfusion insult induced a decrease in the reduced glutathione level which was accompanied by an increase in brain malondialdehyde (MDA), indicative of lipid peroxidation, at $24 \mathrm{~h}$ following the onset of ischemia (Fig. 4C and D). Treatment with magnolol at 0.3 and $1 \mathrm{mg} / \mathrm{kg}$ at $2 \mathrm{~h}$ after the onset of ischemia significantly increased the GSH level, which provided protection for the ischemic brain when measured at $24 \mathrm{~h}$ following ischemia onset, compared with the control group ( $\mathrm{P}<0.05$; Fig. 4D); however, GSSG exhibited no significant difference between the magnolol and control groups. GSH was increased by 109.7-229.8\% and MDA accumulation was reduced by $60.6-80.8 \%$ in the magnolol treatment groups compared with the vehicle-treated controls. Treatment with magnolol at 0.3 and $1 \mathrm{mg} / \mathrm{kg}$ led to significant reductions in the level of MDA $24 \mathrm{~h}$ following ischemia $(\mathrm{P}<0.05$; Fig. 4C).

In situ superoxide $\left(\mathrm{O}_{2^{-}}\right)$detection. In the fluorescent images, intracellular $\mathrm{O}_{2}^{-}$production in the perinuclear area and cytosol was detected via oxidized DHE (HEt) which appeared red and the nuclei were indicated by blue DAPI staining (Fig. 5A). The HEt signals were measured in the cytosol. They were primarily localized to the nuclei and also observed in 
the cytoplasm of the cells, which had a neuronal morphology. HEt signals were observed in the axon- and dendrite-like processes in the vehicle-treated control group. Treatment with magnolol $(1 \mathrm{mg} / \mathrm{kg})$ at $2 \mathrm{~h}$ after the onset of ischemia significantly reduced the relative intensity of the HEt signals in the axon- and dendrite-like processes and the cytosol $(\mathrm{P}<0.05)$. Data are expressed as the percentage of HEt-positive cells relative to the number of DAPI-stained cells. Treatment with magnolol $(1 \mathrm{mg} / \mathrm{kg})$ significantly reduced the percentage of DHE-expressing cells compared with the vehicle-treated control cells. Data are expressed as the ratio percentage of the cytosolic HEt fluorescence intensity relative to the background intensity.

Immunofluorescence staining of 4-HNE and 8-OHdG. In the control group, the immunoreactivity of $8-\mathrm{OHdG}$ was localized to the nuclei in neurons (Fig. 5B). Clear immunoreactivity of 4-HNE was observed in the region of ischemic damage in neuronal dendrites and axons. Compared with the control, magnolol $(1 \mathrm{mg} / \mathrm{kg})$ significantly reduced the number of 4-HNE and 8-OHdG positive cells visible following immunofluorescence staining $(\mathrm{P}<0.05)$. The proportion of cells stained with $4-\mathrm{HNE}$ was reduced by $46.5 \%$ and the proportion of cells stained with $8-\mathrm{OHdG}$ was reduced by $58.0 \%$ in the ischemic brain.

\section{Discussion}

The results of the present study indicate that magnolol is an effective direct radical scavenger with antioxidant action, that is able to inhibit the production of pro-inflammatory cytokines and $\mathrm{NO}_{\mathrm{X}}$ in LPS-stimulated BV2 and RAW 264.7 cells, consistent with previous studies $(7-9,12,15)$. It was also observed that pretreatment with magnolol $(100 \mu \mathrm{M})$ significantly reduced OGD-induced damage in organotypic hippocampal slices. Additionally, delayed treatment with magnolol $(100 \mu \mathrm{M})$ at up to $4 \mathrm{~h}$ post-insult also significantly reduced OGD-induced damage. In animal models, magnolol $(0.3-1 \mathrm{mg} / \mathrm{kg})$ effectively reduced post-stroke increases in oxidative and nitrosative damage, and reduced neutrophil infiltration. In addition, the present study indicated that magnolol upregulated the antioxidant reserves in the ischemic brain, as measured by the level of GSH. Consequently, magnolol effectively reduced in situ $\mathrm{O}_{2}{ }^{-}$accumulation and attenuated membranous lipid peroxidation and the hydroxylation of nucleotides following cerebral ischemia-reperfusion. The i.v. administration of magnolol $(0.01-1 \mathrm{mg} / \mathrm{kg})$ significantly improved the neurobehavioral scores and significantly reduced the area of brain infarction in the animals following transient MCA occlusion. This neuroprotection remained when magnolol $(1 \mathrm{mg} / \mathrm{kg})$ was administered at $2 \mathrm{~h}$ following the onset of ischemia.

A previous study by the present authors demonstrated that magnolol administered intraperitoneally (i.p.) at $50-200 \mathrm{mg} / \mathrm{kg}$, conferred neuroprotection in rats subjected to permanent focal cerebral ischemia (15). Magnolol administered i.p. at larger dosages of $100-200 \mathrm{mg} / \mathrm{kg}$, however, also induced spontaneous hypothermia $(15,27)$. In the present study, magnolol (0.01-1 $\mathrm{mg} / \mathrm{kg}$; i.v.) was effective against ischemic-reperfusion insult in vivo. Notably, these i.v. injections of magnolol at smaller dosages did not notably affect the rats' core body temperatures. The difference between the dosages used for i.v. and i.p. magnolol was $\sim 1: 200$-fold, and further investigation is required to determine the reason for this and to identify the most effective dose and method of administration (17). The results of the present study demonstrated that magnolol was effective when administered i.v. at low doses $(0.01-1 \mathrm{mg} / \mathrm{kg})$, which is closer aligned with the clinical treatment of ischemic stroke patients where i.v. tissue-type plasminogen activator is used.

Magnolol protected the brain against ischemic-reperfusion insults in vivo and in vitro. The neuroprotective effect of magnolol in the present study cannot be accounted for by changes in glucose, heart rate, arterial blood pressure, hemodilution (as measured by blood hematocrit), or changes in LCBF, as the values of these parameters exhibited no significant differences between the vehicle-injected and magnolol-treated groups. The magnolol-mediated neuroprotection observed in the present study was also independent of the magnolol-mediated hypothermic action observed previously when it was administered at large dosages $(200 \mathrm{mg} / \mathrm{kg}$; i.p.) $(15,27)$, as the core temperatures of the rats did not markedly change. OGD-induced damage in the organotypic hippocampal slices was also protected against by magnolol, which had no contributing hypothermic parameters $(15,20)$.

In the present study, it was revealed that magnolol has a therapeutic window of 2-4 h for ischemic-reperfusion insults in vitro. However, post-treatment with magnolol at $4 \mathrm{~h}$ post-insult was ineffective following cerebral ischemia-reperfusion insult in rats (data not shown). Thus, the in vivo and in vitro therapeutic windows may not coincide with the field of neuroprotection. A previous study reported that magnolol (100 mg/kg; i.p.) protected against permanent focal cerebral ischemia when administered up to $4 \mathrm{~h}$ following the injury (15). It is possible that although magnolol at a large dosage $(100 \mathrm{mg} / \mathrm{kg}$, i.p.) did not induce hypothermia within $40 \mathrm{~min}$ of administration in the previous study, it may have caused hypothermia at a later stage of administration, thereby contributing to the extension of the therapeutic window of opportunity to $4 \mathrm{~h}(15,28,29)$. Another theory is that the reperfusion damage may have counteracted the magnolol-induced neuroprotection $(30,31)$. It is possible that a combination of mild hypothermic therapy with magnolol at low dosages $(0.01-1 \mathrm{mg} / \mathrm{kg})$ that do not induce hypothermia may further enhance the neuroprotection observed in the present study $(28,29)$. However, this requires further investigation to confirm. Further studies are also required to clarify the mechanisms underlying the discrepancy between the in vivo and in vitro data obtained in the present study concerning the therapeutic windows.

The present study has demonstrated that magnolol at $0.01 \mathrm{mg} / \mathrm{kg}$ is able to protect the brain against transient focal cerebral ischemia without affecting the MDA, MPO, $\mathrm{NO}_{\mathrm{X}}$, and GSH levels in the ischemic brain. These findings suggest that a different dosing regimen may present with different pharmacologic mechanisms of action $(15,21)$. Additional studies are required to investigate other mechanisms, including the ability to reduce necrosis, autophagy or apoptosis that may also account for the neuroprotective effect of magnolol observed in the present study.

In summary, the present study has revealed that magnolol is a potent radical-scavenger and antioxidant as evaluated 
by antioxidant activity assays in vitro and a series of antioxidant reserve, lipid peroxidation and nitrosative assays in vivo. Magnolol also demonstrated clear anti-nitrosative and -inflammatory effects by suppressing the $\mathrm{NO}_{\mathrm{X}}$ and MPO activity induced by ischemic insults in vivo, and by reducing the production of $\mathrm{NO}$ and proinflammatory cytokines in LPS-stimulated BV2 and RAW 264.7 cells. Additionally, it was demonstrated that the therapeutic window of magnolol was up to $2-4 \mathrm{~h}$, and that magnolol protects against ischemic brain damage, as assessed by the whole animal and organotypic tissue-based assays of transient ischemic stroke, respectively. Consequently, treatment with magnolol resulted in a notable reduction in the accumulation of ROS following ischemia and therefore, attenuated the extent of lipid peroxidation, oxidative DNA damage and final neuronal deaths in the ischemic brain tissues. This indicates that the ability of magnolol to scavenge free radicals may be responsible for its neuroprotective effects following ischemia.

\section{Acknowledgements}

The present study was supported by a grant from the National Science Council of Taiwan (grant no.99-2314-B-006-022-MY3).

\section{Competing interests}

The authors declare there is no competing interest.

\section{References}

1. Traystman RJ, Kirsch JR and Koehler RC: Oxygen radical mechanisms of brain injury following ischemia and reperfusion. J Appl Physiol (1985) 71: 1185-1195, 1991.

2. Bramlett HM and Dietrich WD: Pathophysiology of cerebral ischemia and brain trauma: Similarities and differences. J Cereb Blood Flow Metab 24: 133-150, 2004.

3. Clemens JA: Cerebral ischemia: Gene activation, neuronal injury, and the protective role of antioxidants. Free Radic Biol Med 28: 1526-1531, 2000.

4. Chan PH: Reactive oxygen radicals in signaling and damage in the ischemic brain. J Cereb Blood Flow Metab 21: $2-14,2001$.

5. Lee EJ, Chen HY, Lee MY, Chen TY, Hsu YS, Hu YL, Chang GL and Wu TS: Cinnamophilin reduces oxidative damage and protects against transient focal cerebral ischemia in mice. Free Radic Biol Med 39: 495-510, 2005.

6. Lee EJ, Lee MY, Chen HY, Hsu YS, Wu TS, Chen ST and Chang GL: Melatonin attenuates gray and white matter damage in a mouse model of transient focal cerebral ischemia. J Pineal Res 38: 42-52, 2005.

7. Shen YC, Sung YJ and Chen CF: Magnolol inhibits Mac-1 (CD11b/CD18)-dependent neutrophil adhesion: Relationship with its antioxidant effect. Eur J Pharmacol 343: 79-86, 1998.

8. Wang Y, Li CY, Lin IH, Lee AR and Hu MK: Synthesis and radical scavenging of novel magnolol derivatives. J Pharm Pharmacol 54: 1697-1703, 2002.

9. Chen HY, Hung YC, Lee EJ, Chen TY, Chuang IC and Wu TS: The protective efficacy of magnolol in hind limb ischemia-reperfusion injury. Phytomedicine 16: 976-981, 2009.

10. Chang CP, Hsu YC and Lin MT: Magnolol protects against cerebral ischaemic injury of rat heatstroke. Clin Exp Pharmacol Physiol 30: 387-392, 2003.

11. Teng CM, Yu SM, Chen CC, Huang YL and Huang TF: EDRF-release and $\mathrm{Ca}+(+)$-channel blockade by magnolol, an antiplatelet agent isolated from Chinese herb Magnolia officinalis, in rat thoracic aorta. Life Sci 47: 1153-1161, 1990.

12. Lee MM, Huang HM, Hsieh MT, Chen CS, Yeh FT and Kuo JS: Anti-inflammatory and neuroprotective effects of magnolol in chemical hypoxia in rat cultured cortical cells in hypoglycemic media. Chin J Physiol 43: 61-67, 2000.
13. Lee MM, Hseih MT, Kuo JS, Yeh FT and Huang HM: Magnolol protects cortical neuronal cells from chemical hypoxia in rats. Neuroreport 9: 3451-3456, 1998.

14. Lin YR, Chen HH, Ko CH and Chan MH: Neuroprotective activity of honokiol and magnolol in cerebellar granule cell damage. Eur J Pharmacol 537: 64-69, 2006.

15. Lee WT, Lin MH, Lee EJ, Hung YC, Tai SH, Chen HY, Chen TY and Wu TS: Magnolol reduces glutamate-induced neuronal excitotoxicity and protects against permanent focal cerebral ischemia up to 4 hours. PLoS One 7: e39952, 2012.

16. Watanabe K, Watanabe H, Goto Y, Yamaguchi M, Yamamoto N and Hagino K: Pharmacological properties of magnolol and honokiol extracted from Magnolia officinalis: Central depressant effects. Planta Med 49: 103-108, 1983.

17. Lin SP, Tsai SY, Lee Chao PD, Chen YC and Hou YC: Pharmacokinetics, bioavailability, and tissue distribution of magnolol following single and repeated dosing of magnolol to rats. Planta Med 77: 1800-1805, 2011.

18. Chapman SN, Mehndiratta P, Johansen MC, McMurry TL, Johnston KC and Southerland AM: Current perspectives on the use of intravenous recombinant tissue plasminogen activator (tPA) for treatment of acute ischemic stroke. Vasc Health Risk Manag 10: 75-87, 2014.

19. Lee EJ, Chen HY, Hung YC, Chen TY, Lee MY, Yu SC, Chen YH, Chuang IC and Wu TS: Therapeutic window for cinnamophilin following oxygen-glucose deprivation and transient focal cerebral ischemia. Exp Neurol 217: 74-83, 2009.

20. Chen TY, Lin MH, Lee WT, Huang SY, Chen YH, Lee AC, Lin HW and Lee EJ: Nicotinamide inhibits nuclear factor-kappa $\mathrm{B}$ translocation after transient focal cerebral ischemia. Crit Care Med 40: 532-537, 2012.

21. Tai SH, Hung YC, Lee EJ, Lee AC, Chen TY, Shen CC, Chen HY, Lee MY, Huang SY and Wu TS: Melatonin protects against transient focal cerebral ischemia in both reproductively active and estrogen-deficient female rats: The impact of circulating estrogen on its hormetic dose-response. J Pineal Res 50: 292-303, 2011.

22. Chen TY, Tai SH, Lee EJ, Huang CC, Lee AC, Huang SY and Wu TS: Cinnamophilin offers prolonged neuroprotection against gray and white matter damage and improves functional and electrophysiological outcomes after transient focal cerebral ischemia. Crit Care Med 39: 1130-1137, 2011.

23. Juan WS, Huang SY, Chang CC, Hung YC, Lin YW, Chen TY, Lee AH, Lee AC, Wu TS and Lee EJ: Melatonin improves neuroplasticity by upregulating the growth-associated protein-43 (GAP-43) and NMDAR postsynaptic density-95 (PSD-95) proteins in cultured neurons exposed to glutamate excitotoxicity and in rats subjected to transient focal cerebral ischemia even during a long-term recovery period. J Pineal Res 56: 213-223, 2014.

24. Anderson ME: Determination of glutathione and glutathione disulfide in biological samples. Methods Enzymol 113: 548-555, 1985.

25. Belayev L, Alonso OF, Busto R, Zhao W and Ginsberg MD: Middle cerebral artery occlusion in the rat by intraluminal suture. Neurological and pathological evaluation of an improved model. Stroke 27: 1616-1623, 1996.

26. Clark WM, Rinker LG, Lessov NS, Hazel K, Hill JK, Stenzel-Poore $M$ and Eckenstein F: Lack of interleukin-6 expression is not protective against focal central nervous system ischemia. Stroke 31: 1715-1720, 2000.

27. Hsieh MT, Chueh FY and Lin MT: Magnolol decreases body temperature by reducing 5-hydroxytryptamine release in the rat hypothalamus. Clin Exp Pharmacol Physiol 25: 813-817, 1998.

28. Danton GH and Dietrich WD: Inflammatory mechanisms after ischemia and stroke. J Neuropathol Exp Neurol 62: 127-136, 2003.

29. Ishikawa M, Sekizuka E, Sato S, Yamaguchi N, Inamasu J, Bertalanffy H, Kawase T and Iadecola C: Effects of moderate hypothermia on leukocyte-endothelium interaction in the rat pial microvasculature after transient middle cerebral artery occlusion. Stroke 30: 1679-1686, 1999.

30. Nakashima M, Niwa M, Iwai T and Uematsu T: Involvement of free radicals in cerebral vascular reperfusion injury evaluated in a transient focal cerebral ischemia model of rat. Free Radic Biol Med 26: 722-729, 1999.

31. Sugawara T and Chan PH: Reactive oxygen radicals and pathogenesis of neuronal death after cerebral ischemia. Antioxid Redox Signal 5: 597-607, 2003. 